\title{
Associations between Vaginal Douching Practice and Lower Genital Tract Symptoms and Menstrual Disorders among Young Women: A Search for Risk Modulating Factors
}

\author{
Christopher E. Ekpenyong, Koofreh G. Davies \\ Department of Physiology, College of Health Sciences, University of Uyo, Uyo, Nigeria \\ Email: chrisvon200@yahoo.com
}

Received June 21, 2013; revised July 22, 2013; accepted July 30, 2013

Copyright (C) 2013 Christopher E. Ekpenyong, Koofreh G. Davies. This is an open access article distributed under the Creative Commons Attribution License, which permits unrestricted use, distribution, and reproduction in any medium, provided the original work is properly cited.

\begin{abstract}
This study assessed the associations between vaginal douching practice and the adverse reproductive tract outcomes, and the risk modulating factors among young women. The data source was a cross-sectional population based sample of 1488 women aged 18 - 35 years in a university community. Self-administered socio-demographic and female genital hygiene practices questionnaire were used to survey the participants. The overall prevalence of vaginal douching was 79.8\%. Pelvic pain, vaginal itching, and vaginal discharge were significantly associated with higher odds for douching. Moreover, participants with menstrual disorders such as menorrhagia, oligomenorrhea, and inter-menstrual bleeding douche more often than those without these disorders. Early-onset, higher-frequency, and prolonged douching, as well as douching with commercial vaginal deodorant and inserting the nozzle of the douching tube inside the vagina were associated with higher rate of pelvic and menstrual disorders. The present study revealed a paradoxical relation between vaginal douching and adverse reproductive tract disorders, which supports the hypothesis of confounding by indication. The direction of the association is dependent on several modifiable and un-modifiable risk factors.
\end{abstract}

Keywords: Vaginal Douching Practice; Adverse Reproductive Tract Outcome; Risk Modulating Factor

\section{Introduction}

Lower genital tract symptoms and menstrual irregularities are common presentations of many reproductive tract disorders in women. These disorders can be debilitating and have a substantial impact on health, economy [1], and the quality of life [2]. They are associated with distress and unpleasant experiences during the reproductive years of women [3] and constitute a major threat to the normal physiologic responses of reproductive organs, on which basis, depending on the causes, these symptoms may signal disease conditions associated with future reproductive impairment.

Some women with such problems try several selfprescribed therapeutic measures such as vaginal douching (intravaginal irrigation with water or other fluids) to relieve some of the symptoms and improve their quality of life, to no avail. This is probably because some of the measures themselves are implicated in the etiology/ pathogenesis of disease conditions associated with these symptoms, thereby setting up a vicious cycle in the association. For instance, many women do vaginal douching to relieve their symptoms [4] but several studies [5,6] have implicated vaginal douching itself in the pathogenesis of several diseases that could give rise to those symptoms.

Anecdotal and clinic-based studies suggest that the practice of vaginal douching may be associated with various adverse gynecologic and reproductive outcomes such as bacterial vaginosis and chlamydial infections [7], sexually transmitted infections (STIs) including HIV infection, reduced fertility [8], and cervical cancer [9]. Others include preterm delivery, low birth weight, and ectopic pregnancy [10].

Previous studies have tried to establish the casual pathway through which vaginal douching is associated with these adverse outcomes. It is posited that, vaginal douching disrupts the normal vaginal milieu by destroying the 
acidic environment necessary for the survival of lactobacilli. This decreases the quality and quantity of lactobacilli and causes the subsequent replacement of nonpathogenic with pathogenic flora [11], with an associated decline in vaginal tissue resistance. This decay of the natural vaginal flora paves the way for the infection of multiple agents, leading to associated lower genital tract symptoms (e.g., lower abdominal pain, vaginal discharge, itching, soreness, odor, and dyspareunia) and menstrual disorders (e.g., dysmenorrhea, oligomenorrhea, menorrhagia, and amenorrhea).

Additionally, emerging evidence suggests that vaginal douching may provide a vehicle (pressurized fluid) for the transport of pathogens, aiding the ascend of vaginal infections to regions above the cervix into the uterus, fallopian tubes, or abdominal cavity to cause solitary or widespread pelvic inflammatory diseases (PIDs) with associated sequelae, including chronic pelvic pain, dyspareunia, pelvic adhesions, pyosalpinx, tubo-ovarian abscess, ectopic pregnancy, and infertility [10]. These complications are more common in adolescents and young adults than in older adults because of their high vulnerability to STIs and PIDs [8].

The literature presents inconsistent evidence about the possible etiologic association between vaginal douching and pelvic infections. Although other studies revealed positive and strong associations, others recorded either a complete absence of or only modest associations between vaginal douching and pelvic infections. However, some other studies reported a modest association between hygiene and the prevention of STI, providing a motivation for self-care [12].

These discordant findings raise the question of whether pelvic infections/symptoms prompt douching or whether douching causes lower genital tract symptoms. In which direction the association operates more is controversial and poorly understood, and the literature offers scant information. However, factors analysis has emerged as a useful tool to elucidate these associations. A recent study indicated that the outcome of vaginal douching may depend on several factors, including individual factors, douching technique, indications, and the practice of douching (frequency, duration, type of douching fluid, douching equipment used, and timing of douching). Nevertheless, the effects of these factors may vary from one study population to another. One study may find remarkable effects while other studies may report less or no effects. For instance, although some studies showed that frequent douching immediately preceding PID or STI resulted in increased risk and exacerbation of symptom [7] with unfavorable changes in vaginal ecology, Ness et al. [13] found that the frequency of douching immediately preceding PID or gonococcal/chlamydial genital infections was not different between women who developed and those who did not develop adverse outcomes. Hence, the data obtained from the study of Ness and colleagues do not support the association between douching and the development of PID or STIs among predominantly young African women.

Similarly, several studies conducted in developing countries among douchers who are at higher risk of STIs showed time-and product-dependent decrease in human papilloma virus (HPV), reduced risk of STI/HIV [14], and favorable changes in vaginal ecology [15]. These conflicting findings have also been documented elsewhere [16]. These associations are population/race specific because of the racial/ethnic variations in personal hygiene habits. To the best of our knowledge, few studies have been conducted among Africans, and specifically among female college students; hence, there is a need to explore the association to guide the development of an intervention in order to reduce or discourage vaginal douching among adolescents and young adults who are potential mothers and whose future reproductive performance depends on their present sexual/reproductive behaviors.

\section{Methods}

\subsection{Data Source}

This was a cross-sectional study conducted on 1488 undergraduates, aged 18 - 35 years, randomly recruited between 2011 and 2012, to evaluate the association between vaginal douching practices and lower genital tract symptoms and menstrual disorders. The choice of this sample size was based on the total number (5648) of female students in the university and on the prevalence of vaginal douching (65\%) previously obtained in a pilot survey by a sister institution within the same geographical location. We enhanced the sample size computation by using version 6 of the Epi Info $^{\mathrm{TM}}$ (EPi6) statistical package at $95 \%$ confidence interval. Of the initial number recruited, we excluded 58 women (3.8\%) for not meeting the following inclusion criteria: a female student of the institution, 18 - 35 years old, voluntarily participated, properly completed the questionnaire, has no past or present use of contraception, has no history of regular intense exercise, and without any eating disorder.

\subsection{Measures}

The For this survey, we obtained data from respondents using a 3-section, semistructured, sociodemographic questionnaire on menstrual characteristics and feminine genital tract hygiene practices, which we prepared as described previously [17].

The first section of the questionnaire contained 10 open-ended questions seeking to gather information about the respondents' sociodemographic characteristics: 
age (years), marital status, ethnicity, age at menarche, area of residence, toilet facility, and smoking and alcohol habits. The age of respondents was stratified into 3 groups: 18 - 28, 25 - 30 and 31 - 35 years. Marital status was classified as single and married. Ethnicity was classified into 5groups; Ibibio, Hausa, Igbo, Yoruba and others. Toilet access was classified into private and public. Area of residence was grouped into on-campus and off-campus. Alcohol intake was stratified into drinkers and non-drinkers. Cigarette smoking was grouped into smokers and non-smokers.

The second section contained 8 questions adapted from a menstrual characteristics questionnaire and structured to obtain information about the respondents' menstrual characteristics for the last 6 months. Six broad categories of menstrual characteristics were assessed in the questionnaire, as follows: amenorrhea (absence of menstrual flow for the last 90 days), menorrhagia (heavy flow), oligomenorrhea (light, infrequent, or delayed flow), premenstrual syndrome (associated tension, irritability, and dysphoria before the onset of menstrual flow), dysmenorrhea (painful menstruation), and intermenstrual bleeding (bleeding in between cycles).

To assess the quantity of flow, respondents were asked whether there has been any noticeable increase in the number of sanitary towels used daily during menstruation. Those that reported a noticeable increase were classified as having menorrhagia; those without any increase were assumed to have normal menstrual flow, whereas those with a noticeable decrease were classified as having oligomenorrhea.

The third section was a 14-item assessment scale adapted from the feminine genital hygiene practices and lower genital tract symptoms assessment questionnaire, as described previously [6]. For all women, we asked if they have ever done douching. If they answered "yes", we further asked to state the last time they douched; at what age they started douching; the reason(s) for douching; and whether they experienced associated lower genital tract symptoms, including pelvic pain, dysuria, dyspareunia, vaginal itching, and discharge. We obtained detailed information about their douching practices, such as the frequency of douching per day, duration of fluid flow exposure during each episode of douching, depth of insertion of the nozzle of the douche tube inside the vagina, duration from first douching, and the douching fluid usually used. Based on this information, respondents were divided into 3 groups: 1) current douchers: those who reported douching atleast once in 2 months prior to the survey; 2) former douchers: those who reported douching at some point in the past but had not douched in the past 2 months; and 3) non-douchers: those who reported that they had never douched. Current and former douchers were merged and grouped as douchers, thus douching status was stratified into 2 groups namely douchers and non-douchers.

\subsection{Statistical Analysis}

We descriptively analyzed the data obtained by using frequencies and percentages for categorical variables, and we report the descriptive statistics as means \pm standard deviation for quantitative variables.

We performed multiple logistic regression models to test the association between vaginal douching practice and lower genital tract symptoms and menstrual disorders. This was done with adjustment for possible confounding factors. On the basis of these models, we estimated the odds ratios and 95\% confidence intervals. We enhanced the statistical computations by using the Statistical Package for Social Sciences (SPSS 17.0) at the 5\% significant level.

\subsection{Ethical Consideration}

Ethical approval was obtained from our institution's research ethics committee, and all participants gave consent after being informed in detail of the aims of the study.

\section{Result}

From the data obtained from 1488 women who participated in this survey, we found that most of them were neither single (85.4\%), within the ages of 20 and 30 years $(78 \%)$, and neither drinker (58.7\%) nor smokers (97.5\%). Their average age at menarche was $13.64 \pm$ 2.44 years. The overall prevalence of vaginal douching was $79.8 \%$, and there were significant differences in demographic variables and age at menarche $(P<0.001)$ between douchers and non-douchers (Table 1).

The lower genital tract symptoms with significant higher odds for vaginal douching were pelvic pain (odds ratio $[\mathrm{OR}]_{\text {Adjusted }}=2.10,95 \%$ confidence interval $[95 \%$ CI] 1.060 - 4.172, $P=0.033)$, vaginal itching $\left(\mathrm{OR}_{\text {Adjusted }}\right.$ $=3.69$, 95\% CI $1.848-7.350, P<0.001)$, and vaginal discharge $\left(\mathrm{OR}_{\text {Adjusted }}=1.25,95 \%\right.$ CI $1.00-1.565, P=$ 0.045). We obtained a non-significant association for other lower genital tract symptoms $(P<0.05)$ (Table 2).

Similarly, we observed significant differences in the incidence of some menstrual disorders between douchers and non-douchers. Douchers had higher odds for developing menstrual disorders such as menorrhagia $\left(\mathrm{OR}_{\mathrm{Ad}-}\right.$ justed $=2.14,95 \%$ CI $1.005-4.546, P=0.049$ ), oligomenorrhea $\left(\mathrm{OR}_{\text {Adjusted }}=1.85\right.$, 95\% CI $1.392-2.457, P$ $<0.001)$, and intermenstrual bleeding $\left(\mathrm{OR}_{\text {Adjusted }}=1.60\right.$, 95\% CI $1.199-2.136, P<0.001)$ than non-douchers (Table 3).

Most of the douchers in this survey douche to relieve vaginal symptoms (27.4\%), during bathing (21.2\%), for 
Table 1. Demographic characteristics of respondents.

\begin{tabular}{|c|c|c|c|c|}
\hline Demographic variables & Total no. of respondents $(n=1488)$ & Douchers $(n=1188)$ & Nondouchers $(n=300)$ & $P$-value \\
\hline \multicolumn{5}{|l|}{ Age (years) } \\
\hline $18-24$ & $284(19.1)$ & $202(17.0)$ & $82(27.3)$ & \multirow{3}{*}{$<0.001^{* *}$} \\
\hline $25-30$ & $1127(75.7)$ & $927(78.0)$ & $200(66.7)$ & \\
\hline $31-35$ & $77(5.2)$ & $59(5.0)$ & $18(6.0)$ & \\
\hline \multicolumn{5}{|l|}{ Marital status } \\
\hline Single & $1307(87.8)$ & $1015(85.4)$ & $8(2.7)$ & \multirow[t]{2}{*}{$<0.001^{*}$} \\
\hline Married & $181(12.2)$ & $173(14.6)$ & $292(97.3)$ & \\
\hline \multicolumn{5}{|l|}{ Ethnicity } \\
\hline Ibibio & $1163(78.2)$ & $955(80.4)$ & $208(69.3)$ & \multirow{5}{*}{$<0.001^{* *}$} \\
\hline Hausa & $47(3.2)$ & $35(2.9)$ & $12(4.0)$ & \\
\hline Igbo & $172(11.6)$ & $119(10.0)$ & $53(17.7)$ & \\
\hline Yoruba & $95(6.4)$ & $71(6.0)$ & $24(8.0)$ & \\
\hline Others & $11(0.7)$ & $8(0.70)$ & $3(1.0)$ & \\
\hline \multicolumn{5}{|l|}{ Toilet access } \\
\hline Private & $540(36.3)$ & $463(39.0)$ & $77(25.7)$ & \multirow[t]{2}{*}{$<0.001^{* *}$} \\
\hline Public & $948(63.7)$ & $725(61.0)$ & $223(74.3)$ & \\
\hline \multicolumn{5}{|l|}{ Area of residence } \\
\hline Off campus & $621(41.7)$ & $533(44.9)$ & $88(29.3)$ & \multirow[t]{2}{*}{$<0.001^{* * *}$} \\
\hline On campus & 867 (58.3) & $655(55.1)$ & $212(70.7)$ & \\
\hline \multicolumn{5}{|l|}{ Alcohol intake } \\
\hline Nondrinker & $874(58.7)$ & $649(54.6)$ & $225(75.0)$ & \multirow{2}{*}{$<0.001^{* *}$} \\
\hline Drinker & $614(41.3)$ & $539(45.4)$ & $75(25.0)$ & \\
\hline \multicolumn{5}{|l|}{ Smoking habits } \\
\hline Nonsmoker & 1431 (96.2) & $1158(97.5)$ & $273(91.0)$ & $<0.001^{* *}$ \\
\hline Smoker & $57(3.8)$ & $30(2.5)$ & $27(9.0)$ & \\
\hline Age at menarche (means \pm SD) & $13.64 \pm 2.44$ & $13.79 \pm 2.05$ & $12.66 \pm 3.99$ & $<0.001^{* *}$ \\
\hline
\end{tabular}

${ }^{* *} P<0.01$, significant at $1 \%$.

Table 2. Multiple logistic regression analysis showing the association between lower genital tract symptoms and vaginal douching (odds ratio and $95 \%$ confidence interval).

\begin{tabular}{ccccccc}
\hline Lower genital tract symptoms & Total $(n=1488)$ & Douchers $(n=1188)$ & Nondouchers $(n=300)$ & Adjusted OR & $95 \%$ CI & P-value \\
\hline Pelvic pain & $428(28.8)$ & $280(65.4)$ & $148(34.6)$ & 2.10 & $1.060-4.172$ & $0.033^{*}$ \\
Vaginal discharge & $237(15.9)$ & $122(51.5)$ & $155(48.5)$ & 1.25 & $1.00-1.565$ & $0.045^{*}$ \\
Vaginal itching & $461(31.0)$ & $301(65.3)$ & $160(34.7)$ & 3.69 & $1.848-7.350$ & $<0.001^{* *}$ \\
Dyspareunia (pain on coitus) & $193(13.0)$ & $115(59.6)$ & $78(40.4)$ & 0.19 & $0.013-2.802$ & 0.225 \\
Dysuria & $98(6.6)$ & $69(70.4)$ & $29(29.6)$ & 0.44 & $0.046-4.267$ & 0.480 \\
\hline
\end{tabular}

Adjusted for age, marital status, ethnicity, toilet access, area of residence, alcohol intake, and smoking habit. $P<0.05$, significant at $5 \%$; ${ }^{* *}<0.01$, significant at $1 \%$.

Table 3. Multiple logistic regression analysis showing the association between menstrual disorders and vaginal douching practice.

\begin{tabular}{ccccccc}
\hline Menstrual disorders & Total $(137)$ & Doucher $(n=97)$ & Nondoucher $(n=40)$ & Adjusted OR & $95 \%$ CI & $P$-value \\
\hline Menorrhagia & $52(38.0)$ & $39(75.0)$ & $13(25.0)$ & 2.14 & $1.005-4.546$ & $0.049^{*}$ \\
Amenorrhea & $23(16.8)$ & $14(60.9)$ & $9(39.1)$ & 1.33 & $0.963-1.846$ & 0.083 \\
Dysmenorrhea & $31(22.6)$ & $19(61.3)$ & $12(38.7)$ & 0.29 & $0.025-4.744$ & 0.468 \\
Pre-menstrual syndrome & $46(33.6)$ & $27(58.7)$ & $19(41.3)$ & 1.34 & $0.958-1.869$ & 0.088 \\
Oligomenorrhea & $64(46.7)$ & $48(75.0)$ & $16(25.0)$ & 1.85 & $1.392-2.457$ & $<0.001^{* *}$ \\
Intermenstrual bleeding & $57(41.6)$ & $42(73.7)$ & $15(26.3)$ & 1.60 & $1.199-2.136$ & $<0.001^{* *}$ \\
\hline
\end{tabular}

Adjusted for age, age at menarche, marital status, ethnicity, toilet access, area of residence, alcohol intake, smoking habit, and stress. ${ }^{*} P<0.05$, significant at $5 \% ;{ }^{* *} P<0.01$, significant at $1 \%$. 
general hygiene (17.4\%), after sexual intercourse (16.3\%), after menses (9.2\%), when not feeling fresh (7.5\%), and for contraception (1\%) (Table 4).

Furthermore, the odds for lower genital tract symptoms were higher among respondents who douche to relieve vaginal symptoms $\left(\mathrm{OR}_{\text {Adjusted }}=2.00,95 \% \mathrm{CI}\right.$ 1.366 - 2.937, $P=0.001)$ and for general hygiene $\left(\mathrm{OR}_{\mathrm{Ad}-}\right.$ justed $=1.55,95 \%$ CI $1.217-2.571, P=0.002)$. Similarly, there were increased odds for menstrual disorders in those who douche to relieve vaginal symptoms $\left(\mathrm{OR}_{\text {Adjusted }}\right.$ $=2.67,95 \%$ CI 1.936-7.621, $P<0.002$ ), during bathing $\left(\mathrm{OR}_{\text {Adjusted }}=2.12,95 \% \mathrm{CI} 0.221-20.493, P<0.514\right)$, for general hygiene $\left(\mathrm{OR}_{\text {Adjusted }}=1.34,95 \% \mathrm{CI} 0.407\right.$ - 4.215, $P=0.615)$, to feel fresh $\left(\mathrm{OR}_{\text {Adjusted }}=1.07,95 \%\right.$ CI 0.303 - 3.796, $\mathrm{P}=0.412)$, and after menses (OR $=1.01,95 \%$ CI 0.495 - 2.075, $P=0.970$ ).

Finally, the ages at first douche, frequency of douching, duration of each douching episode, depth of inser tion of the nozzle of the douching tube, type of douching fluid, and duration from first douche were significantly associated with the development of lower genital tract symptoms. We obtained similar results for menstrual disorders but found a non-significant association with the duration of fluid exposure and type of douching fluid used (Table 5).

Table 4. Reasons for douching among douchers $(n=1188)$.

\begin{tabular}{ccc}
\hline Reasons for douching & Number & Percentage (\%) \\
\hline After menses & 109 & 9.2 \\
After sexual intercourse & 194 & 16.3 \\
When not feeling fresh & 89 & 7.5 \\
To relieve vaginal symptoms & 325 & 27.4 \\
During bathing & 252 & 21.2 \\
General hygiene & 207 & 17.4 \\
Prevent pregnancy & 12 & 1.0 \\
\hline
\end{tabular}

Table 5. Multiple logistic regression analysis showing the association between lower genital tract symptoms, menstrual disorders, and douching practice.

\begin{tabular}{|c|c|c|c|c|c|c|}
\hline \multirow{2}{*}{ Douching practice } & \multicolumn{3}{|c|}{ Lower genital tract symptoms } & \multicolumn{3}{|c|}{ Menstrual disorders } \\
\hline & OR & $95 \% \mathrm{CI}$ & $P$-value & OR & $95 \%$ CI & P-value \\
\hline \multicolumn{7}{|l|}{ Age at $1^{\text {st }}$ douche (years) } \\
\hline$<12$ & 1.44 & $0.760-2.717$ & 0.265 & 1.13 & $0.996-1.284$ & 0.058 \\
\hline $12-25$ & 1.82 & $1.355-2.429$ & $<0.001$ & 1.53 & $1.384-1.928$ & $0.025^{*}$ \\
\hline$>25$ & 1.00 & & & 1.00 & & \\
\hline \multicolumn{7}{|c|}{ Frequency (number of times per day) } \\
\hline Once & 1.00 & & & 1.00 & & \\
\hline $2-4$ & 1.95 & $1.317-2.897$ & 0.001 & 1.23 & $1.011-1.499$ & $0.039^{*}$ \\
\hline$>4$ & 2.43 & $1.566-3.773$ & $<0.001$ & 1.79 & $1.426-2.241$ & $<0.001^{* *}$ \\
\hline \multicolumn{7}{|c|}{ Duration of exposure to fluid (minutes) } \\
\hline $1-5$ & 1.00 & & & 1.00 & & \\
\hline $6-10$ & 1.18 & $0.993-1.391$ & 0.061 & 1.15 & $0.982-1.352$ & 0.065 \\
\hline$>10$ & 1.76 & $1.457-2.134$ & $<0.001$ & 1.35 & $0.991-1.827$ & 0.058 \\
\hline \multicolumn{7}{|l|}{ Douching fluid used } \\
\hline Water only & 1.00 & & & 1.00 & & \\
\hline Water and soap & 1.86 & $1.436-2.277$ & 0.032 & 1.47 & $1.215-1.781$ & $0.029^{*}$ \\
\hline Commercial vagina deodorant & 1.60 & $0.189-13.488$ & 0.668 & 1.43 & $1.082-1.882$ & $0.012^{*}$ \\
\hline Others & 1.19 & $0.148-9.595$ & 0.870 & 1.14 & $0.989-1.324$ & 0.071 \\
\hline \multicolumn{7}{|l|}{ Duration from 1st douche (years) } \\
\hline$<1$ & 1.00 & & & 1.00 & & \\
\hline $1-6$ & 1.25 & $1.018-1.523$ & 0.033 & 1.06 & $0.642-1.749$ & 0.083 \\
\hline$>6$ & 1.79 & $1.431-2.254$ & $<0.001$ & 1.54 & $1.289-1.831$ & 0.037 \\
\hline \multicolumn{7}{|l|}{ Reason for douching } \\
\hline To prevent pregnancy & 1.00 & & & 1.00 & & \\
\hline To feel fresh & 1.07 & $0.196-5.861$ & 0.936 & 1.07 & $0.303-3.796$ & 0.412 \\
\hline After menses & 1.08 & $0.179-6.650$ & 0.936 & 1.01 & $0.495-2.075$ & 0.970 \\
\hline During bathing & 1.06 & $0.161-6304$ & 0.995 & 2.12 & $0.221-20.493$ & 0.514 \\
\hline To relieve vaginal symptoms & 2.00 & $1.366-2.937$ & $<0.001$ & 2.67 & $1.936-7.621$ & $0.002^{* *}$ \\
\hline
\end{tabular}

${ }^{*} \mathrm{P}<0.05$, significant at $5 \% ;{ }^{* *} \mathrm{P}<0.01$, significant at $1 \%$. 


\section{Discussion}

In the present study, we found that the presence of lower genital tract symptoms and menstrual disorders were significantly associated with higher odds for vaginal douching by the respondents. We also observed that respondents who started vaginal douching between the ages of 12 and 25 years, those who douche 4 times per week, and those who usually use commercial vaginal douching products had a higher risk of developing lower genital tract symptoms and menstrual irregularities. We noted a similarly increased risk among participants who usually insert the nozzle of the douching tube inside the vagina and those who had been douching for $>6$ years before this study. We also observed that most women douche to relieve vaginal symptoms, while bathing, as a hygienic measure, and after coitus and menstruation. These factors were associated with higher risks of developing lower genital tract symptoms and menstrual irregularities.

These results therefore favor the hypothesis of confounding by indication; that is, vaginal douching performed by most women to relieve lower genital tract symptoms is itself a precipitating factor for the said symptoms. However, the direction and the strength of the association depend on several factors. Interaction between these factors could result in a vicious cycle in the relation. Such factors include age, marital status, education level, socioeconomic status, parity, race, culture/ethnicity, smoking habits, and sexual behavior. For instance, the age bracket of most respondents in this survey corresponds with the age at first menstruation and also the age at sexual debut. Research findings indicate that most adolescents and young adults have their first menstruation and sexual experience at about this period [18], leading to a higher rate of douching $[1,11,18]$, as most women may douche regularly at about this age owing to the false belief that the vagina is unclean during menstruation and sexual intercourse [17]. In studies conducted among African Americans and white women in the southern United States, most women reported douching after menstruation and sex because of their concern about odor and cleanliness [19]. A higher rate of douching with associated complications is therefore expected in women with a higher frequency of sexual intercourse, such as sex workers [17] and women with many partners [20].

Moreover, adolescents are more vulnerable to contracting STIs and therefore douche more often than adults. The epithelium of the exocervix in adolescents is more susceptible to sexually transmitted infective agents (bacterial and viral) than that in adults owing to its larger transformation zone [1], and reproductive hormones during adolescence and young adulthood cause consid- erable physical and tissue change that may increase these women's vulnerability to STIs [21]. Adolescents are therefore more prone to STI and PID with the associated complications, including lower genital tract symptoms, menstrual disorders, and infertility. This could explain the dose-response reduction in fecund ability reported by Baird et al. [8], which was more marked in adolescents and young adults under 25 years of age. The practice/ technique of douching (frequency, duration of each douching episode, fluid used in douching, and duration from first douche and indication for douching) was also implicated. Knowledge about these risk factors offers encouraging opportunities for intervention through improved medical technique and behavior modification.

Of added significance in the casual relation between douching practice and onset of complications is the dose and time effect. Participants who douched $>4$ times per week, with each episode lasting for more than 10 minutes, as well as those who had been douching for $>6$ years before the study had higher risks of lower genital tract symptoms and menstrual disorders. These findings are supported by several similar findings in the literature. Jenny et al. [22] found that the frequency of douching and recent douching was associated with endometritis and upper genital tract infections in women with normal vaginal flora. Similarly, Scholes et al. [7], in a population-based case-control study, demonstrated that women who douche at least once a week had a higher estimated risk than those who douche less often. In another study by Heng et al. [23], the frequency of douching was significantly associated with genitourinary symptoms, and such symptoms were more prevalent in participants who douche from several times a week to once a day. Paradoxically, similar symptoms were less prevalent in those who douche more than once a day. These discordant results could probably be due to the characteristics of the studied population, the timing of douching, the type of douching products used, the douching technique, and the indication for douching. These assertions gain support from the results of several studies conducted in developing countries, especially among women who were at higher risk of acquiring sexually transmitted disease. In these studies, the authors found that, depending on the duration, indication, and products used, adverse health effects were less common among women who douche [14].

Concerning the role of the composition of the douching fluid used, prior studies have documented conflicting findings. Different douching products may cause positive or negative outcomes. In a short-term use of a medicated douche preparation (Betadine Medicated Douche) in the symptomatic treatment of minor vaginal symptoms (discharge, odor, pruritus, erythema, burning, and discomfort), Beaton et al. [24] found that $94 \%$ of the affected 
women were completely cured and 4\% were only partially relieved. In all, 95\% of the patients responded favorably. Another study by Chow et al. [25] found that women using commercial douching preparations had a 4.4 times risk of ectopic pregnancy compared with never douchers, whereas women using water only or water with vinegar had no elevated risk [26]. Consistent with the results of previous studies, the frequency of douching showed a positive association with lower genital tract symptoms and menstrual disorders among douchers compared with nondouchers in the present study. However, this association w6as absent in other studies [20]. These conflicting results could be due to the characteristics of the study population, such as the variability in participants' responses. Other studies have reported about race-specific douching effects [7,10]. Jossen et al. [27] demonstrated a positive association between douching and PID with associated complications only in whites but not among African American women.

In further investigations of the casual relation between douching and adverse outcomes, various studies have implicated the timing of douching in relation to a woman's menstrual cycle. Douching around the time of ovulation, when the cervical os gapes open and the mucus thins in response to the changing serum estrogen level, has been associated with a higher risk of ascending infection [9]. Moreover, douching in the immediate postcoital period may be particularly risky because the douching solution may propel and facilitate the entry of pathogens from the upper vagina into the endocervical canal [28]. Evidence-based studies have shown that the internal cervical os may remain open during and shortly after menses or pregnancy termination, and also that the composition and consistency of the mucus varies during the menstrual cycle, compromising its effectiveness as a plug [29]. Similarly, higher-intensity/higher-pressure douching, such as that produced by a douching device that has a nozzle with a single, unshielded control opening or a douche bag and disposable products, is associated with a higher risk of PIDs and ectopic pregnancy. Conversely, douching may provide a vehicle (pressurized fluid) for the transport of pathogens from the lower vagina into the upper pelvic region [30]. Moreover, the presence of an occlusion in the vaginal opening produces a slightly higher pressure than otherwise.

In the present study, participants who douche by placing the nozzle of the tube right inside the vagina, thereby reducing the distance to the vaginal cavity and maximizing the pressure effect, had a higher risk of developing lower genital tract symptoms and menstrual disorders. Such high-pressure fluid flow may enhance the spread of lower genital infection to the upper pelvic structures, thus precipitating the onset of PID and sequelae. Other studies have implicated the douching device as a determiner of the douching outcome. With a Water Works douching device made of stainless steel, Chatwani et al. [31] did not observe any associated complication or symptoms of pelvic infection during the length of their study; rather, they observed a reduction or elimination of vaginal odor without adversely affecting the vaginal ecosystem. This is probably because the device was designed in such a way that water is directed downward away from the cervical os and is also gravity fed, as against a device that possess a nozzle with a single, unshielded central opening or a douche bag and disposable products, which are associated with complications of PID [32].

\section{Conclusions}

The findings of this study support the previous studies that showed a significant association between vaginal douching and adverse gynecologic and reproductive outcomes. Nevertheless, the direction of the association depends on several modifiable and unmodifiable confounders. Hence, these factors should be the main focus of any public health action and clinical practice to discourage vaginal douching.

This study is limited by its cross-sectional nature. There is a likelihood of oversampling those symptoms that persisted for a long time and less likelihood of capturing those that lasted only for a short time. Moreover, this cross-sectional study cannot accurately attribute to the lower genital tract symptoms and menstrual irregularities to vaginal douching only. Furthermore, self-reported symptoms could carry a recall bias, leading to over- or underestimation of the severity, as the symptoms could range from nonspecific to specific and the severity could range from mild, to moderate, to severe. Despite these limitations, this study has the strength of having a large sample size, providing a fair representation of the target population.

\section{REFERENCES}

[1] D. M. Rein, W. J. Kassler, K. L. Irwin and L. Rabiee, "Direct Medical Cost of Pelvic Inflammatory Disease and Its Sequelae Decreasing, but Still Substantial,” Obstetrics and Gynecology, Vol. 95, No. 3, 2000, pp. 397-402. doi:10.1016/S0029-7844(99)00551-7

[2] M. X. Dawood, "Non-Steroidal Anti-Inflammatory Drugs and Changing Attitudes towards Dysmenorrhea," American Journal of Medicine, Vol. 84, No. 5, 1988, pp. 23-29. doi:10.1016/0002-9343(88)90473-1

[3] A. K. Chappel, M. Hassell, M. Nicolson and J. Cantrill, "You Don't Really Feel You Can Function Normally: Women's Perception and Personal Management of Vaginal Thrush," Journal of Reproduction and Infant Psychology, Vol. 18, No. 4, 2000, pp. 309-319. doi:10.1080/713683045

[4] R. L. Sweet, “Gynecologic Conditions and Bacterial Vag- 
inosis: Implications for the Non-Pregnant Patient," Infectious Diseases in Gynecology, Vol. 8, No. 3-4, 2000, pp. 184-190.

[5] M. R. Chacko, C. A. Kozaine, M. Regard and P. B. Smith, "The Relationship between Vaginal Douching and Vaginal Infection in Young Women," Journal of Pediatric and Adolescent Gynecology, Vol. 5, No. 3, 1992, pp. 171-176.

[6] B. O. Wang, X. Li, B. Stanton, H. Yang, X. Fang, R. Zhao, et al., "Vaginal Douching, Condom Use and Sexual Transmitted Infections among Chinese Sex Workers," Sexually Transmitted Diseases, Vol. 32, No. 11, 2005, pp. 696-702. doi:10.1097/01.olq.0000175403.68410.ec

[7] D. Scholes, J. R. Daling, A. Stergachis, N. S. Weiss, S. P. Wang and J. T. Grayston, "Vaginal Douching as a Risk Factor for Acute Pelvic Inflammatory Disease,” Obstetrics and Gynecology, Vol. 81, No. 4, 1993, pp. 601-606.

[8] D. D. Baird, C. R. Weinberg, L. F. Volgt and J. R. Daling, "Vaginal Douching and Reduced Fertility," American Journal of Public Health, Vol. 86, No. 6, 1996, pp. 844850. doi:10.2105/AJPH.86.6.844

[9] J. Zhang, A. G. Thomas and E. Leybovich, "Vaginal Douching and Adverse Health Effect: A Meta-Analysis," American Journal of Public Health, Vol. 87, No. 7, 1997, pp. 1207-1211. doi:10.2105/AJPH.87.7.1207

[10] J. L. Martino and S. H. Vermund, "Vaginal Douching: Evidence for Risk or Benefits to Women's Health,” Epidemiology Review, Vol. 24, No. 2, 2002, pp. 109-124. doi:10.1093/epirev/mxf004

[11] J. C. Abma, A. Chandra, W. D. Mosher, L. Peterson and L. Piccino, "Fertility, Family Planning and Women's Health: New Data from 1995 National Survey of Family Growth,” Vital Health Statistics, Series 23, National Center for Health Statistics, Washington DC, 1997, 114p.

[12] D. Sunay, E. Kaya and Y. Ergun, "Vaginal Douching Behavior of Women and Relationship among Vaginal Douching and Vaginal Discharge and Demographic Factors," Journal of Turkish Society of Obstetrics and Gynecology, Vol. 8, No. 4, 2011, pp. 264-271. doi:10.5505/tjod.2011.57805

[13] R. B. Ness, S. L. Hiller, K. E. Kip, H. E. Richter, D. E. Soper, C. A. Stamm, et al., "Douching, Pelvic Inflammatory Diseases, and Incident Gonococcal and Chlamydial Genital Infection in a Cohort of High Risk Women,” American Journal of Epidemiology, Vol. 161, No. 2, 2005, pp. 186-195. doi:10.1093/aje/kwi025

[14] G. Gresenguet, J. K. Kreiss, M. K. Chapko, S. L. Hillier and N. S. Weiss, "HIV Infection and Vaginal Douching in Central Africa,” AIDS, Vol. 11, No. 1, 1997, pp. 101-106. doi:10.1097/00002030-199701000-00015

[15] C. Tevi-Benissan, L. Belec, M. Levy, V. Schnieder-Fauveau, A. S. Mohamed, M. C. Hallouin, et al., "In Vivo Semen-Associated $\mathrm{pH}$ Neutralization of Cervicovaginal Secretions," Clinical and Diagnostic Laboratory Immunology, Vol. 4, No. 3, 1997, pp. 367-374.

[16] S. I. Pavlova and L. Tao, "In Vitro Inhibition of Commercial Douche Products against Vaginal Microflora," Infectious Diseases in Obstetrics and Gynecology, Vol. 8, No. 2, 2000, pp. 99-104.
[17] M. K. Oh, J. S. Merchant and P. Brown, "Douching Behavior in High-Risk Adolescents. What Do They Use, When and Why Do They Douche?” Journal of Pediatric and Adolescent Gynecology, Vol. 15, No. 2, 2002, pp. 8385. doi:10.1016/S1083-3188(01)00148-6

[18] M. K. Oh, E. Funkhouser, T. Simpson, P. Brown and J. Merchant, "Early Onset of Vaginal Douching Is Associated with False Beliefs and High-Risk Behavior," Sexually Transmitted Diseases, Vol. 30, No. 9, 2003, pp. 689693. doi:10.1097/01.OLQ.0000079526.04451.DE

[19] B. Lichtenstein and T. R. Nansel, "Women's Douching Practices and Related Attitudes: Findings from Four Focus Groups,” Women's Health, Vol. 31, No. 2-3, 2000, pp. 117-131. doi:10.1300/J013v31n02_06

[20] L. Annang, D. M. Grimley and E.W. Hook 3rd, "Vaginal Douching Practices among Black Women at Risk: Exploring Douching Prevalence, Reasons for Douching and Sexually Transmitted Disease Infection,” Sexually Transmitted Diseases, Vol. 33, No. 4, 2006, pp. 215-219. doi:10.1097/01.olq.0000205046.11916.c5

[21] J. W. Krashin, E. H. Koumans, A. C. Bradshaw-Sydnor, J. R. Braxton, W. E. Secor, M. K. Sawyer, et al., "Trichomonas Vaginalis Prevalence, Incidence, Risk Factor and Antibiotic Resistance in an Adolescent Population," Sexually Transmitted Diseases, Vol. 37, No. 7, 2012, pp. 440410.

[22] L. M. Jenny and H. V. Sten, "Vaginal Douching: Evidence for Risks or Benefits to Women's Health,” Epidemiology Review, Vol. 24, No. 2, 2002, pp. 109-124. doi:10.1093/epirev/mxf004

[23] L. S. Heng, H. Yatsuya, S. Morita and J. Sakamoto, "Vaginal Douching in Cambodian Women: Its Prevalence and Association with Vaginal Candidiasis," Journal of Epidemiology, Vol. 20, No. 1, 2010, pp. 70-76. doi:10.2188/jea.JE20081046

[24] J. H. Beaton, F. Gibson and M. Roland, "Short Term Use of a Medicated Douche Preparation in the Symptomatic Treatment of Minor Irritation in Some Case Associated with Infertility,” International Journal of Fertility, Vol. 29, No. 2, 1984, pp. 109-112.

[25] W. H. Chow, J. R. Darling, N. S. Weiss, D. E. Moore and R. Soderstrom, "Vaginal Douching as a Potential Risk Factor for Tubal Ectopic Pregnancy,” American Journal of Obstetrics and Gynecology, Vol. 153, No. 7, 1985, pp. 727-729.

[26] S. E. Peters, C. M. Beck-Sague, C. E. Farshy, I. Gibson, K. A. Kubota, F. Solomon, et al., "Behavior Associated with Neisseria gonorrhea and Chlamydia trachomatis. Cervical Infection among Young Women Attending Adolescent Clinics,” Clinical Pediatrics, Vol. 39, No. 3, 2000, pp. 173-177. doi:10.1177/000992280003900307

[27] M. O. Jossens, B. Eskenazi, J. Schachter and R. L. Sweet, "Risk Factors for Pelvic Inflammatory Disease: A Case Control Study,” Sexually Transmitted Diseases, Vol. 23, No. 3, 1996, pp. 239-247. doi:10.1097/00007435-199605000-00014

[28] R. N. Shain, S. T. Perdue, J. M. Piper, A. E. Holden, J. D. Champion, E. R. Newton, et al., "Behaviors Changed by Intervention Are Associated with Reduced STD Recur- 
rence: The Importance of Context in Measurement," Sexually Transmitted Diseases, Vol. 29, No. 9, 2002, pp. 520-527. doi:10.1097/00007435-200209000-00005

[29] E. Odeblad, "The Biophysical Aspects of Cervical Mucus,” In J. A. Jordan and A. Singer, Eds., The Cervix, WB Saunders, London, 1976, pp. 155-163.

[30] M. J. Rosenberg and R. S. Phillips, "Does Douching Promote Ascending Infection?” Journal of Reproductive Medicine, Vol. 37, No. 11, 1992, pp. 930-938.

[31] A. J. Chatwani, S. Hassan, S. Rahimi, S. Jeronis and V.
Dandolu, "Douching with Water Works Device for Perceived Vaginal Odor with or without Complaints of Discharge in Women with No Infections Cause of Vaginitis: A Pilot Study," Infective Disorders in Obstetrics and Gynecology, Vol. 2006, 2006, Article ID: 95618.

[32] Health and Human Services, "Vaginal Douche Product for Over-the-Counter Human Use Establishment of a Monograph. Advanced Notice of Proposal Rulemaking," Federal Registry, Vol. 48, No. 199, 1983, pp. 4669346729. 